\title{
Bioprosthetic valves and atrial fibrillation: Direct anticoagulants or warfarin
}

Samir R. Kapadia, MD, FACC, ${ }^{a}$ and Lars G. Svensson, MD, PhD ${ }^{\mathrm{b}, \mathrm{c}}$

Feature Editor's Introduction-Warfarin was first developed in the 1940s as rat poison and was clinically first used in the 1950s in humans as an anticoagulant. Since then, we have been in search of a suitable alternative that can offer our patients a more reliable and predictable physiologic effect, as well as less disruption in their day-to-day life. It was not until 2010 that dabigatran (Pradaxa, Boehringer Ingelheim, Ridgefield, Conn) was approved by the Food and Drug Administration, but was not approved for use in patients with valvular heart disease. Since then, a slew of novel agents have come to market. These have been welcomed with open arms by the medical community, so much so that prescriptions for direct-acting oral anticoagulants now exceed those for warfarin. However, our valvular heart disease community has not been able to actively thrust itself into this ongoing evolution in medical care until recently.

We must look to our surgical valve recipients with atrial fibrillation and their needs. As knowledge and evidence build, we must strive to provide them with the most effective and convenient therapy options available. Where evidence is lacking, we have a duty to determine which is the best possible option. Direct-to-patient marketing has been effective, and there is an eagerness to provide easier and more convenient anticoagulation regimens among physicians and patients alike. However, we must not lose sight of these being currently an off-label use and the paucity of evidence available to justify this.

It is an exciting time for atrial fibrillation novel and multimodal therapy; data coming out are encouraging in regard to efficacy and safety in the population with bioprosthetic valves, as seen in the Rivaroxaban for Valvular Heart DiseasE and atRial Fibrillation trial. The tide may be swelling, but the pendulum hasn't swung yet. As these "novel" therapies become more commonplace

\footnotetext{
From the a Department of Cardiovascular Medicine, Heart, Vascular, and Thoracic Institute, Cleveland Clinic, Cleveland, Ohio; ${ }^{\mathrm{b}}$ Department of Thoracic and Cardiovascular Surgery, Heart, Vascular, and Thoracic Institute, Cleveland Clinic, Cleveland, Ohio; and ${ }^{\mathrm{c}}$ Aorta Center, Heart, Vascular, and Thoracic Institute, Cleveland Clinic, Cleveland, Ohio.

Received for publication March 17, 2021; revisions received April 30, 2021; accepted for publication May 6, 2021; available ahead of print June 26, 2021.

Address for reprints: Lars G. Svensson, MD, PhD, Heart, Vascular, and Thoracic Institute, Cleveland Clinic, 9500 Euclid Ave, J1-227, Cleveland, OH 44195 (E-mail: svenss1@ccf.org).

J Thorac Cardiovasc Surg 2023;165:71-5

$0022-5223 / \$ 36.00$

Copyright (c) 2021 by The American Association for Thoracic Surgery https://doi.org/10.1016/j.jtcvs.2021.05.051
}

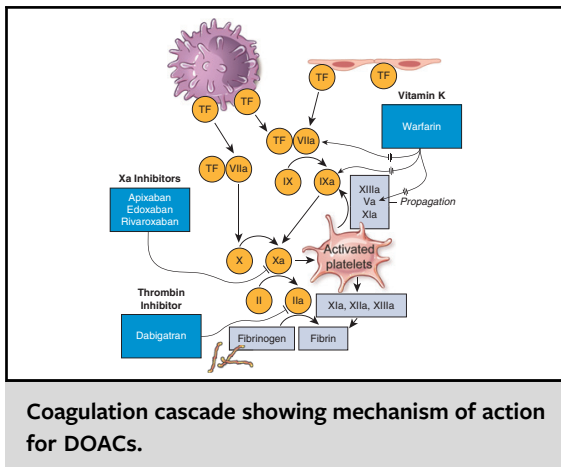

$$
\begin{aligned}
& \text { CENTRAL MESSAGE } \\
& \text { Initial safety and efficacy data are } \\
& \text { encouraging for DOACs increas- } \\
& \text { ingly used in patients with AF and } \\
& \text { bioprosthetic heart valves, } \\
& \text { although more studies are } \\
& \text { warranted. }
\end{aligned}
$$$$
\text { Source article: N Engl J Med. } 2020 \text { Nov }
$$$$
\text { 26;383(22):2117-2126. https://doi.org/10.1056/NEJMO }
$$$$
\text { a2029603. Epub } 2020 \text { Nov } 14 .
$$

See Commentaries on pages 76 and 78.

and more evidence comes out on their use, they will cease to be novel and become the standard of care for our patients. We must look to the future and be diligent to effectively and safely extend the convenience, reliability, and, most important, effectiveness of these therapies to as large a population as possible. Let's continue to push the medical field firmly into the 21st century.

\section{Rafael Duran, MD, and Nahush A. Mokadam, MD}

Strategies for stroke prevention in atrial fibrillation (AF) have evolved significantly over the last decade because of the availability of various pharmacologic, device-related, rhythm-control options. Our understanding of stroke risk and risk benefits for these different treatment options is rapidly evolving, especially for specific patient populations. Valvular or nonvalvular AF distinction has been identified in landmark randomized trials, with a slightly different definition for valvular AF. ${ }^{1-4}$ The American Heart Association/ American College of Cardiology guidelines for AF define 
nonvalvular AF as the absence of rheumatic mitral stenosis, a mechanical or bioprosthetic heart valve, or mitral valve (MV) repair. ${ }^{5}$ Patients with bioprosthetic heart valves constitute an important group, because AF is common in these patients.

\section{Mechanisms of Action for Coumadin and Direct Anticoagulants}

Coumadin, the vitamin $\mathrm{K}$ antagonist (VKA), was the mainstay of therapy for several decades in patients with AF who were at high risk of stroke. However, VKA is fraught with several limitations, including routine need for monitoring, variable individual bioavailability due to polymorphisms of cytochrome P450 enzyme and vitamin $\mathrm{K}$ epoxide reductase genes, and food interactions due to vitamin $\mathrm{K}$ content and many possible drug interactions. Furthermore, the therapeutic window is relatively small. Beyond pharmacokinetic limitations, vitamin $\mathrm{K}$ inhibition is nonselective, leading to inhibition of vitamins $\mathrm{K} 1$ and $\mathrm{K} 2$. Vitamin $\mathrm{K} 2$ is involved in the inhibition of arterial calcification and is essential for the c-carboxylation of matrix Gla proteins. These proteins are vital for keeping a normal balance of cellular calcium uptake. Vitamin K2 inhibition results in vascular calcification. ${ }^{6}$ There is some concern that chronic use of VKAs can result in native valvular calcification. ${ }^{7}$ If a similar phenomenon is seen in the prosthetic valves, it can be detrimental for their durability. Further investigations and more data are warranted in these areas.
There are several newer medications that target the coagulation system at different steps, leading to specific effects on coagulation cascade. Our understanding of coagulation cascade has evolved over the last decade. The classic description of intrinsic and extrinsic pathways has merged into tissue-factor-dependent activation of the coagulation system, termed the "tissue factor pathway." 8 This change in thinking is related to better understanding of factor XII, which is now better described as a factor responsible for clot propagation and stabilization rather than clot initiation. Tissue factor pathway for coagulation is summarized in Figure 1, showing the newer anticoagulants inhibiting $\mathrm{Xa}$ or thrombin. Direct anticoagulants (DOACs) have predictable bioavailability and effectiveness, and therefore have a fixed-dose administration without the need to monitor the level of anticoagulation. They also act faster and have a shorter duration of action compared with warfarin.

\section{Direct Anticoagulants in Atrial Fibrillation and Bioprosthetic Valves}

In pivotal $\mathrm{AF}$ trials, all $\mathrm{DOAC}$ trials performed better in terms of stroke prevention and bleeding complications compared with warfarin (Table 1$)^{1-4}$; these trials excluded patients with hemodynamically significant mitral stenosis and mechanical valves, whereas some trials included patients with bioprosthetic valves or prior valve repairs. However, patients with bioprosthetic valves and, in particular, bioprosthetic MVs were limited. The Apixaban

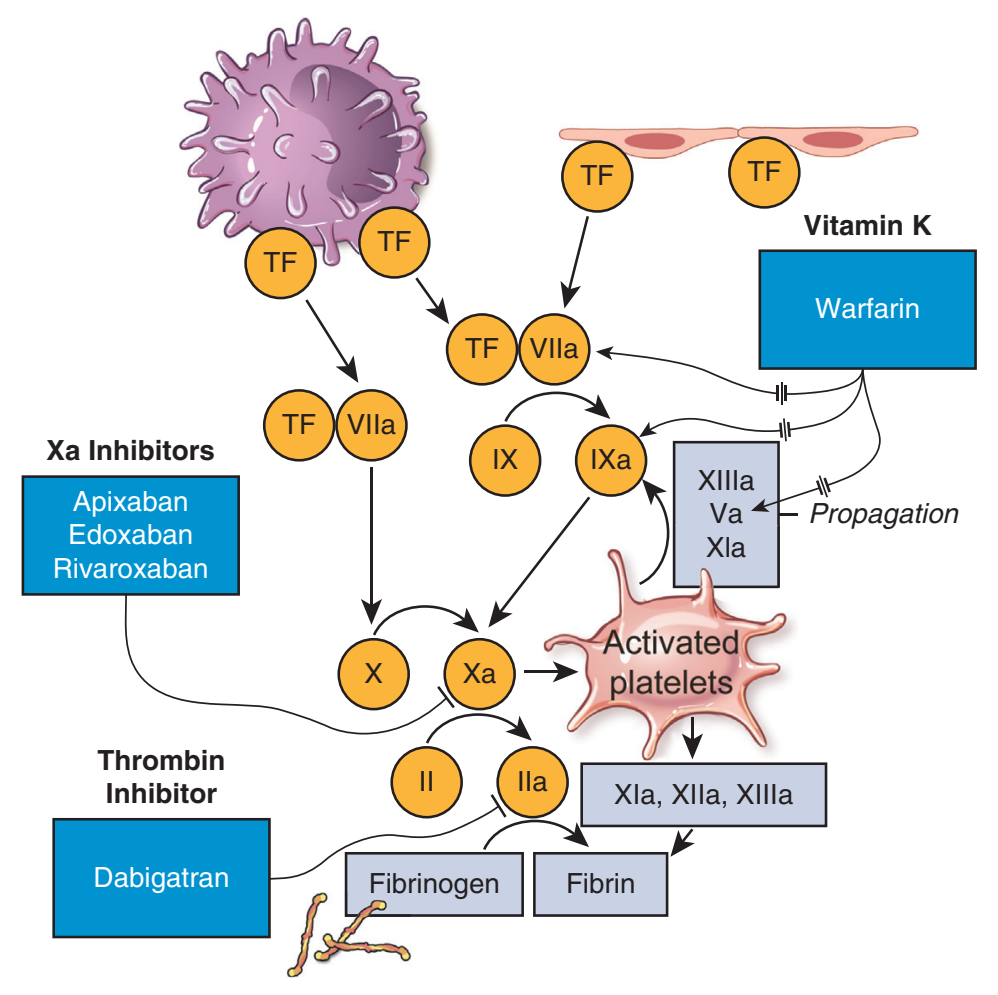

FIGURE 1. Coagulation cascade showing mechanism of action for DOACs. $T F$, Tissue factor. 
for Reduction in Stroke and Other Thromboembolic Events in Atrial Fibrillation trial had 31 such patients, and the Effective Anticoagulants with Factor Xa Next Generation AF had 131., ${ }^{910}$ The recent landmark Rivaroxaban for Valvular Heart DiseasE and atRial Fibrillation (RIVER) trial investigated the safety and efficacy of rivaroxaban compared with warfarin in 1005 patients with bioprosthetic $\mathrm{MV}$ and $\mathrm{AF} .{ }^{11}$

Patients with bioprosthetic valves form a unique group of patients with AF. Valvular or nonvalvular AF with a mitral bioprosthesis has a higher risk of stroke compared with those without. ${ }^{12}$ Further, AF with mitral regurgitation has a higher risk of stroke compared with those without mitral regurgitation. ${ }^{13}$ It makes intuitive sense that safety and effectiveness of DOACs should be similar in patients with prosthetic valves. However, a prior study with dabigatran in patients with mechanical valves found warfarin was better for stroke prevention compared with DOAC, and this raised concerns even for patients with bioprosthetic valves. ${ }^{14}$ The RIVER trial, a multicenter, open-label, randomized, noninferiority trial with blinded outcome adjudication from 49 sites in Brazil, was specifically designed to address this question. ${ }^{15}$ Patients with a bioprosthetic MV and AF or flutter were randomly assigned (1:1) to $20 \mathrm{mg}$ of rivaroxaban once daily ( $15 \mathrm{mg}$ in those with creatinine clearance $<50 \mathrm{~mL} / \mathrm{min}$ ) or dose-adjusted warfarin once daily (target international normalized ratio 2.0-3.0). The follow-up period was 12 months. The primary outcome was a composite of allcause mortality, stroke, transient ischemic attack, major bleeding, valve thrombosis, systemic embolism, and hospitalization for heart failure. Secondary outcomes included individual components of the primary composite outcome, bleeding events, and venous thromboembolism. Rivaroxaban was found to be noninferior to warfarin with respect to the mean time until primary composite outcome of death, major cardiovascular events, or major bleeding at 12 months. When looking at individual components of the composite outcome for patients receiving rivaroxaban compared with warfarin, death from cardiovascular or thromboembolic cause was similar $(3.4 \%$ vs $5.1 \%$, hazard ratio, $0.65 ; 95 \%$ confidence interval [CI], 0.35-1.20), incidence of stroke was less with rivaroxaban $(0.6 \%$ vs $2.4 \%$, hazard ratio, $0.25 ; 95 \% \mathrm{CI}, 0.07-0.88$ ), and major bleeding was similar (1.4\% vs $2.6 \%$, hazard ratio, $0.54 ; 95 \% \mathrm{CI}$, 0.21-1.35). Taken together, rivaroxaban provides a feasible treatment option for these patients.

\section{Unresolved Questions About Direct Anticoagulants in Atrial Fibrillation and Bioprosthetic Valves}

There are several interesting clinical queries that warrant future study. One question is whether these data can be applied to the management of postoperative AF after valve replacement. There were 189 patients $(18.8 \%)$ within 3 months of MV replacement in this study. In this subgroup, the incidence of a primary outcome event was $6.4 \%$ in the rivaroxaban group and $18.9 \%$ in the warfarin group (hazard ratio, $0.31 ; 95 \%$ CI, 0.12-0.79). Although individual events, including stroke $(1.1 \%$ vs $4.2 \%)$ and major bleeding $(1.1 \%$ vs $5.6 \%)$, were not statistically significantly different, they allowed for confidence in the overall

TABLE 1. Randomized clinical trials of direct anticoagulants versus warfarin in patients with atrial fibrillation

\begin{tabular}{|c|c|c|c|c|c|}
\hline Trial & RE-LY & ROCKET-AF & ARISTOTLE & ENGAGE AF & RIVER \\
\hline Drug & $\begin{array}{l}\text { Dabigatran } \\
\text { LD: } 110 \mathrm{mg} \\
\text { HD: } 150 \mathrm{mg}\end{array}$ & $\begin{array}{l}\text { Rivaroxaban } \\
20 \mathrm{mg}\end{array}$ & $\begin{array}{l}\text { Apixaban } \\
5 \mathrm{mg} \text { BID }\end{array}$ & $\begin{array}{l}\text { Edoxaban } \\
\text { LD: } 30 \mathrm{mg} \\
\text { HD: } 60 \mathrm{mg}\end{array}$ & $\begin{array}{l}\text { Rivaroxaban } \\
20 \mathrm{mg}\end{array}$ \\
\hline No. of patients & 18,113 & 14,264 & 18,201 & 21,505 & 1005 \\
\hline $\begin{array}{l}\text { Stroke or systemic embolism, } \\
\text { drug vs warfarin }\end{array}$ & $\begin{array}{l}\text { LD: } 1.53 \% \text { vs } 1.69 \% \\
\text { HD: } 1.11 \% \text { vs } 1.69 \%\end{array}$ & $2.1 \%$ vs $2.4 \%$ & $1.27 \%$ vs $1.6 \%$ & $\begin{array}{l}\text { LD: } 2.01 \% \text { vs } 1.5 \% \\
\text { HD: } 1.18 \% \text { vs } 1.5 \%\end{array}$ & $.6 \%$ vs $2.6 \%$ \\
\hline $\begin{array}{l}\text { Major bleeding, drug vs } \\
\text { warfarin }\end{array}$ & $\begin{array}{l}\text { LD: } 2.71 \% \text { vs } 3.36 \% \\
\text { HD: } 3.11 \% \text { vs } 3.36 \%\end{array}$ & $5.6 \%$ vs $5.4 \%$ & $2.13 \%$ vs $3.09 \%$ & $\begin{array}{l}\text { LD: } 61 \% \text { vs } 3.43 \% \\
\text { HD: } 2.75 \% \text { vs } 3.43 \%\end{array}$ & $1.4 \%$ vs $2.6 \%$ \\
\hline $\begin{array}{l}\text { Excluded patients with } \\
\text { valvular HD }\end{array}$ & $\begin{array}{l}\text { Prosthetic heart valves } \\
\text { Hemodynamically } \\
\text { significant MS }\end{array}$ & $\begin{array}{l}\text { Prosthetic heart valves } \\
\text { Hemodynamically } \\
\text { significant MS }\end{array}$ & $\begin{array}{c}\text { Mechanical valves } \\
\text { Hemodynamically } \\
\text { significant MS }\end{array}$ & $\begin{array}{c}\text { Mechanical valves } \\
\text { Hemodynamically } \\
\text { significant MS }\end{array}$ & $\begin{array}{c}\text { Mechanical valves } \\
\text { Hemodynamically } \\
\text { significant MS }\end{array}$ \\
\hline $\begin{array}{l}\text { Prosthetic valves or } \\
\text { valve repair, } n\end{array}$ & 0 & 0 & $\begin{array}{l}156 \\
104(0.6 \%) \text { replacement } \\
52(0.3 \%) \text { repair }\end{array}$ & $\begin{array}{l}191 \\
\text { All replacement }\end{array}$ & $\begin{array}{l}1005 \\
\text { All with MV } \\
\text { replacement }\end{array}$ \\
\hline $\begin{array}{l}\text { Stroke, drug vs } \\
\text { warfarin }\end{array}$ & NA & NA & $2.77 \%$ vs $1.64 \%$ & $\begin{array}{l}\text { LD: HR } 0.53, P=.31 \\
\text { HD: HR } 0.37, P=.15\end{array}$ & $.6 \%$ vs $2.4 \%$ \\
\hline $\begin{array}{l}\text { Major bleeding, drug } \\
\text { vs warfarin }\end{array}$ & NA & NA & $5.87 \%$ vs $6.44 \%$ & $\begin{array}{l}\text { LD: HR } 0.12, P=.045 \\
\text { HD: HR } 0.50, P=.26\end{array}$ & $1.4 \%$ vs $2.6 \%$ \\
\hline
\end{tabular}

RE-LY, Randomized Evaluation of the Long-Term Anticoagulation Therapy; ROCKET, Rivaroxaban Once-daily, Oral, Direct Factor Xa Inhibition Compared with Vitamin K Antagonism for Prevention of Stroke and Embolism Trial; ARISTOTLE, Reduction in Stroke and Other Thromboembolic Events in Atrial Fibrillation; ENGAGE, Effective Anticoagulants with Factor Xa Next Generation; $A F$, atrial fibrillation; RIVER, Rivaroxaban for Valvular Heart DiseasE and atRial Fibrillation; $L D$, low-dose; $H D$, high-dose; $B I D$, twice daily; $M V$, mitral valve; $M S$, mitral stenosis; $N A$, not available; $H R$, hazard ratio. 
finding of the trial. How to apply these data for patients with postoperative $\mathrm{AF}$ remains debatable and warrants further study. The second question is how to apply these data for patients undergoing maze procedures or left atrial appendage ligations at the time of mitral surgery. ${ }^{16}$ Furthermore, it is imperative to determine the strategy of using DOACs with rhythm control (medications, percutaneous, or surgical ablations) or appendage occlusion (ligation, clips, percutaneous devices) for patients with prior MV surgery.

\section{Direct Anticoagulants in Transcatheter Aortic Valve Replacement}

There are several important studies in the prosthetic valve population with DOACs that are of interest. There is an increased interest in patients with transcatheter aortic valve replacement (TAVR) without AF regarding prevention of leaflet thrombosis. Leaflet thrombosis is most commonly subclinical but has been associated with increased valve gradients and ischemic neurologic events. ${ }^{17-19}$ The first large randomized study in this arena, the Global Study Comparing a rivAroxaban-based Antithrombotic Strategy to an antipLatelet-based Strategy After Transcatheter aortIc vaLve rEplacement to Optimize Clinical Outcomes, showed that in patients without an established indication for oral anticoagulation after successful TAVR, treatment strategy including rivaroxaban at a dose of $10 \mathrm{mg}$ daily was associated with a higher risk of death or thromboembolic complications and a higher risk of bleeding than an antiplatelet-based strategy. ${ }^{20}$ Interestingly, in a substudy of a trial involving patients without an indication for long-term anticoagulation who had undergone successful TAVR, a rivaroxaban-based antithrombotic strategy was more effective than an antiplatelet-based strategy in preventing subclinical leaflet motion abnormalities. ${ }^{21}$ The ongoing Anti-Thrombotic Strategy After Trans-Aortic Valve Implantation for Aortic Stenosis (ATLANTIS) trial will also provide some important information on this subject. In the experimental arm of this trial, patients receive apixaban $5 \mathrm{mg}$ twice daily or a reduced dose of $2.5 \mathrm{mg}$ twice daily according to the drug label or when combined with antiplatelet therapy. In the control arm, patients receive VKA therapy, if there is an indication for oral anticoagulation or antiplatelet therapy alone (single or dual) or the combination of both if needed. The primary study end point is the composite of all-cause death, transient ischemic attack/stroke, myocardial infarction, symptomatic valve thrombosis, pulmonary embolism, deep venous thrombosis, systemic embolism, and life-threatening, disabling, or major bleeding, according to the Valve Academic Research Consortium definitions with study outcomes reported in 2021. It is also important to note that observational studies of DOACs after TAVR have shown prevention of subclinical leaflet thrombosis. ${ }^{22-24}$

\section{Reversal of Direct Anticoagulants}

One concern with using DOACs has been the possibility of rapid reversal of DOACs in cases of uncontrolled bleeding. It is now possible to reverse the effects of DOACs in actively bleeding patients when local measures to stop bleeding are not effective. Table 2 lists the laboratory testing that can help to determine the level of anticoagulation with specific agents and potential antidotes. Commonly available tests such as prothrombin time, partial thromboplastin time, and thrombin time can rule out excess DOACs, but not therapeutic levels of certain agents. Although available in large centers, more specific tests, such as diluted thrombin time, ecarin clotting time, and anti-factor Xa activity assay, do not provide rapid responses. Specific antidotes such as idarucizumab for dabigatran and andexanet $\alpha$ for rivaroxaban and apixaban are ideal for reversal of these agents. Andexanet $\alpha$ may work for edoxaban, but studies are ongoing regarding efficacy. Different formulations of prothrombin complex concentrate overwhelm the clotting system and can be partially helpful in reversing some effects of DOACs, but they also increase the risk of thrombotic complications. These agents should be

TABLE 2. Testing and reversal of anticoagulation in patients receiving direct anticoagulants

\begin{tabular}{lllllll}
\hline Agent & ECT and dTT ${ }^{*}$ & APTT & PT & Anti Xa activity level & Antidote & $\begin{array}{c}\text { May help, will not reverse } \\
\text { total anticoagulation, } \\
\text { potentially thrombogenic }\end{array}$ \\
\hline Dabigatran & Increased & Increased & Unchanged & Unchanged & $\begin{array}{l}\text { Idarucizumab } \\
\text { Ciraparantag } \dagger\end{array}$ & 3 or 4 factor PCC or aPCC \\
Apixaban & Unchanged & Unchanged & Normal or increased & Increased & $\begin{array}{l}\text { Andexanet } \alpha \\
\text { Ciraparantag } \dagger\end{array}$ & 3 or 4 factor PCC or aPCC \\
Rivaroxaban & Unchanged & Unchanged & Increased & Increased & $\begin{array}{l}\text { Andexanet } \alpha \\
\text { Ciraparantag } \dagger\end{array}$ & 3 or 4 factor PCC or aPCC \\
Edoxaban & Unchanged & Unchanged & Normal or increased & Increased & $\begin{array}{l}\text { Andexanet } \alpha \ddagger \\
\text { Ciraparantag } \dagger\end{array}$ & 3 or 4 factor PCC or aPCC \\
\hline
\end{tabular}

$E C T$, Ecarin clotting time; $d T T$, dilute thrombin time; $A P T T$, activated partial thromboplastin time; $P T$, prothrombin time; $P C C$, prothrombin complex concentrate; $a P C C$, activated prothrombin complex concentratess. *Thrombin time, not dTT; if normal can rule out high levels of dabigatran. †Not yet US Food and Drug Administration approved.

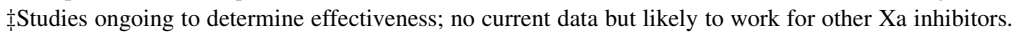


considered as a second choice in the event that specific antidotes are not readily available.

\section{CONCLUSIONS}

Familiarity with these medications is increasing among internists and cardiologists, leading to greater use in different patient populations. In the coming years, resultant data on DOACs will become available for all subgroups of patients with valvular heart disease. Patients with rheumatic heart disease and those with mechanical valves are some who are being enrolled in clinical trials. ${ }^{25,26}$ Until conclusive data are available on these patient subgroups, DOAC use is not indicated in these patients. The role of DOACs in transcatheter and surgical aortic and MV repair will be another important area for research trials. Current data provide some basis for considering DOAC for patients with AF in bioprosthetic valves. The RIVER trial intends to explore the safety and efficacy of rivaroxaban compared with VKA. The trial focuses on patients with AF who also have bioprosthetic MVs. Large, multinational studies are warranted with long-term, conclusive data with clinical outcomes, including stroke and bleeding.

\section{Conflict of Interest Statement}

The authors reported no conflicts of interest.

The Journal policy requires editors and reviewers to disclose conflicts of interest and to decline handling or reviewing manuscripts for which they may have a conflict of interest. The editors and reviewers of this article have no conflicts of interest.

\section{References}

1. Giugliano RP, Ruff CT, Braunwald E, Murphy SA, Wiviott SD, Halperin JL, et al. Edoxaban versus warfarin in patients with atrial fibrillation. N Engl J Med. 2013; 369:2093-104.

2. Patel MR, Mahaffey KW, Garg J, Pan G, Singer DE, Hacke W, et al. Rivaroxaban versus warfarin in nonvalvular atrial fibrillation. N Engl J Med. 2011;365:883-91.

3. Granger CB, Alexander JH, McMurray JJV, Lopes RD, Hylek EM, Hanna M, et al. Apixaban versus warfarin in patients with atrial fibrillation. $N$ Engl J Med. 2011;365:981-92.

4. Connolly SJ, Ezekowitz MD, Yusuf S, Eikelboom J, Oldgren J, Parekh A, et al. Dabigatran versus warfarin in patients with atrial fibrillation. $N$ Engl J Med. 2009;361:1139-51.

5. January CT, Wann LS, Calkins H, Chen LY, Cigarroa JE, Cleveland JC, et al. 2019 AHA/ACC/HRS focused update of the 2014 AHA/ACC/HRS guideline for the management of patients with atrial fibrillation: a report of the American College of Cardiology/American Heart Association task force on clinical practice guidelines and the Heart Rhythm Society. J Am Coll Cardiol. 2019; 74:104-32.

6. Hasific S, Øvrehus KA, Gerke O, Hallas J, Busk M, Lambrechtsen J, et al. Extent of arterial calcification by conventional vitamin $\mathrm{K}$ antagonist treatment. PLoS One. 2020:15:e241450.

7. Sønderskov PS, Lindholt JS, Hallas J, Gerke O, Hasific S, Lambrechtsen J, et al. Association of aortic valve calcification and vitamin K antagonist treatment. Eur Heart J Cardiovasc Imaging. 2020;21:718-24.

8. Vojacek JF. Should we replace the terms intrinsic and extrinsic coagulation pathways with tissue factor pathway? Clin Appl Thromb Hemost. 2017;23:922-7.

9. Avezum A, Lopes RD, Schulte PJ, Lanas F, Gersh BJ, Hanna M, et al. Apixaban in comparison with warfarin in patients with atrial fibrillation and valvular heart disease: findings from the Apixaban for Reduction In STroke and Other ThromboemboLic Events in atrial fibrillation (ARISTOTLE) Trial. Circulation. 2015; 132:624-32.

10. Carnicelli AP, De Caterina R, Halperin JL, Renda G, Ruff CT, Trevisan M, et al Edoxaban for the prevention of thromboembolism in patients with atrial fibrillation and bioprosthetic valves. Circulation. 2017;135:1273-5.

11. Guimãraes HP, de Barros ESPGM, Liporace IL, Sampaio RO, Tarasoutchi F, Paixão M, et al. A randomized clinical trial to evaluate the efficacy and safety of rivaroxaban in patients with bioprosthetic mitral valve and atrial fibrillation or flutter: rationale and design of the RIVER trial. Am Heart J. 2021;231: 128-36.

12. Philippart R, Brunet-Bernard A, Clementy N, Bourguignon T, Mirza A Angoulvant D, et al. Oral anticoagulation, stroke and thromboembolism in patients with atrial fibrillation and valve bioprosthesis. The Loire valley atrial fibrillation project. Thromb Haemost. 2016;115:1056-63.

13. Philippart R, Brunet-Bernard A, Clementy N, Bourguignon T, Mirza A Babuty D, et al. Prognostic value of CHA2DS2-VASc score in patients with 'non-valvular atrial fibrillation' and valvular heart disease: the Loire valley atrial fibrillation project. Eur Heart J. 2015;36:1822-30.

14. Eikelboom JW, Connolly SJ, Brueckmann M, Granger CB, Kappetein AP, Mack MJ, et al. Dabigatran versus warfarin in patients with mechanical heart valves. $N$ Engl J Med. 2013;369:1206-14.

15. Guimaraes HP, Lopes RD, de Barros ESPGM, Liporace IL, Sampaio RO, Tarasoutchi F, et al. Rivaroxaban in patients with atrial fibrillation and a bioprosthetic mitral valve. $N$ Engl J Med. 2020;383:2117-26.

16. Murashita T, Rankin JS, Wei LM, Roberts HG, Alkhouli MA, Badhwar V. Ora anticoagulation may not be necessary for patients discharged in sinus rhythm after the Cox Maze IV procedure. J Thorac Cardiovasc Surg. 2018;155: 997-1006.

17. Tian Z, Li T, Ma S. Impact of leaflet thrombosis on hemodynamics and clinical outcomes after bioprosthetic aortic valve replacement: a meta-analysis. Clin Car diol. 2020;43:468-74.

18. Tang L, Lesser JR, Schneider LM, Burns MR, Gössl M, Garberich R, et al. Prospective evaluation for hypoattenuated leaflet thickening following transcatheter aortic valve implantation. Am J Cardiol. 2019;123:658-66.

19. Chakravarty T, Søndergaard L, Friedman J, De Backer O, Berman D, Kofoed KF, et al. Subclinical leaflet thrombosis in surgical and transcatheter bioprosthetic aortic valves: an observational study. Lancet. 2017;389: 2383-92.

20. Dangas GD, Tijssen JGP, Wohrle J, Søndergaard L, Gilard M, Möllmann H, et al A controlled trial of rivaroxaban after transcatheter aortic-valve replacement. $N$ Engl J Med. 2020;382:120-9.

21. De Backer O, Dangas GD, Jilaihawi H, Leipsic JA, Terkelsen CJ, Makkar R, et al Reduced leaflet motion after transcatheter aortic-valve replacement. $N$ Engl J Med. 2020;382:130-9.

22. Kawashima H, Watanabe Y, Hioki H, Kozuma K, Kataoka A, Nakashima M, et al. Direct oral anticoagulants versus vitamin $\mathrm{K}$ antagonists in patients with atrial fibrillation after TAVR. JACC Cardiovasc Interv. 2020;13: 2587-97.

23. Jochheim D, Barbanti M, Capretti G, Stefanini GG, Hapfelmeier A, Zadrozny M et al. Oral anticoagulant type and outcomes after transcatheter aortic valve replacement. JACC Cardiovasc Interv. 2019;12:1566-76.

24. Butt JH, De Backer O, Olesen JB, Gerds TA, Havers-Borgerson A, Gislason GH et al. Vitamin K antagonists vs direct oral anticoagulants after transcatheter aortic valve implantation in atrial fibrillation. Eur Heart J Cardiovasc Pharmacother 2021;7:11-9.

25. Jawitz OK, Wang TY, Lopes RD, Chavez A, Boyer B, Kim H, et al. Rationale and design of PROACT Xa: a randomized, multicenter, open-label, clinical trial to evaluate the efficacy and safety of apixaban versus warfarin in patients with a mechanical On-X Aortic Heart Valve. Am Heart J. 2020; 227:91-9.

26. Karthikeyan G, Connolly SJ, Ntsekhe M, Benz A, Rangarajan S, Lewis G, et al The INVICTUS rheumatic heart disease research program: rationale, design and baseline characteristics of a randomized trial of rivaroxaban compared to vitamin $\mathrm{K}$ antagonists in rheumatic valvular disease and atrial fibrillation. Am Heart J. 2020;225:69-77.

Key Words: anticoagulation, antithrombotic, coagulation cascade, stroke prevention, TAVR 